\title{
Expanding Expertise: Investigating a Musician's Experience of Music Performance
}

\author{
Andrew Geeves (andrew.geeves@psy.mq.edu.au), Doris McIlwain (dmcilwai@psy.mq.edu.au) \\ Department of Psychology, Macquarie University \\ Sydney, NSW 2109 Australia \\ John Sutton (jsutton@maccs.mq.edu.au), Wayne Christensen (wchriste@maccs.mq.edu.au) \\ Macquarie Centre for Cognitive Science, Macquarie University \\ Sydney, NSW 2109 Australia
}

\begin{abstract}
Seeking to expand on previous theories, this paper explores the AIR (Applying Intelligence to the Reflexes) approach to expert performance previously outlined by Geeves, Christensen, Sutton and McIlwain (2008). Data gathered from a semi-structured interview investigating the performance experience of Jeremy Kelshaw (JK), a professional musician, is explored. Although JK's experience of music performance contains inherently uncertain elements, his phenomenological description of an ideal performance is tied to notions of vibe, connection and environment. The dynamic nature of music performance advocated by the AIR approach is illustrated by the strategies that JK implements during performance. Through executing these strategies, JK attempts to increase the likelihood of vibe and connection by selectively exercising agency over performance variables within his control. In order to achieve this, JK must engage in ongoing monitoring of his performance, whereby the spotlight of his attention pans across a vast array of disparate performance processes (and levels within these processes) in order to ascertain how he can most effectively meet the specific demands of a given performance situation. It is hoped that future research compiling data from numerous interviews and sources as well as using different research methodologies will further unlock the potential that the AIR approach holds for understanding expert performance.
\end{abstract}

\section{Introduction}

Walking on stage, the powerful presence of the expert musician ripples across the audience, generating collective silence. The first notes ring out loud and clear, opening channels of communication between audience and performer and initiating unique connection. Bodies twist and turn with the rhythm, lyrics resonate and the music unites audience and performer, resulting in moments of heightened enjoyment. The experience etches itself in memory, lingering with the performer and audience long after the final encore.

How is this sort of performance possible? What does an expert musician attend to, ignore, think and feel during performance? To what extent is an expert musical performance pre-planned and how much of it emerges from the demands placed on the performer by their immediate environment? What sorts of processes and strategies does an expert musician execute in order to produce such a performance? At the level of phenomenology, what is the experience of giving a performance such as this like?
Questions about expertise in music performance, such as those raised by this example, link to a larger body of existing work centered on conceptualisations of expertise. Extant research has been characterised by a particular tension stemming from debate around the relative primacy of two different types of processes in expert performance: top-down and bottom-up processes. Top-down processes involve engagement with overarching, higher-order cognitive structures; pre-planned models of how to respond to certain situational demands that have been constructed by the chunking, organisation and rehearsal of certain information in a particular way. Bottom-up processes, on the other hand, involve being attuned to [or in tune with] one's corporeal reality in a given moment, and [or :] responding to situational demands in a way that feels right at a bodily level. Traditionally, theorists have been divided, tending to foreground either the role of higher order, topdown processes or the role of embodied, bottom-up processes in expert performance.

\section{Prioritising Top-Down Processes}

Chaffin (2002) emphasises the crucial nature of top-down processes in expert performance in his work with concert pianist Gabriella Imreh. Chaffin posits that Imreh's expert performance results from her following of performance cues. These higher order cognitive cues come to be embedded in Imreh's performance routine through a laborious process of chunking, organisation and practice adopted in rehearsal. Drawing on Ericsson \& Kintsch's (1995) theory of Long-Term Working Memory (LTWM), Chaffin theorises that Imreh's expertise lies (as that of any expert) in her ability to chunk and organise information effectively in the rehearsal stage, a skill strengthened by thousands of hours of previous practice. During rehearsal, performance cues come to be aligned with particular locations in the score, triggering recall of information held in LTWM. Come performance time, information encoded in LTWM automatically fills in the gaps between performance cues. Imreh's performance then, relies on the effective retrieval and utilisation of a previously rehearsed and consolidated mental road map signposted by performance cues. Assuming adequate rehearsal procedures, Imreh need only follow this mental road map to be guaranteed a consistent and expert performance. 


\section{Prioritising Bottom-Up Processes}

Phenomenological theorists such as Dreyfus (2002) have asserted the primacy of bottom-up processes in expert performance. According to Dreyfus, the rigidity of mental representations means that they are fundamentally inadequate foundations on which to build a theory of expertise. In contrast to some researchers, over-reliance on top-down processes is viewed as having the potential to interrupt, rather than facilitate, expert performance. By thinking about her performance, the expert risks overthinking what she is doing, thereby interrupting the embodied sequences of actions and reactions which, according to Dreyfus, constitute true expert performance. For Dreyfus, an examination of more embodied processes is needed in order to explain the dynamicism and flexibility which characterise expertise. Borrowing Merleau-Ponty's notion of an intentional arc, Dreyfus claims that the transition from novice to expert entails a turning away from set rules and mental representations of bodily action in favour of a more intuitive, embodied 'smooth coping' which feels right. Through becoming increasingly attuned to specific situations, an expert comes to achieve maximum grip, a series of optimal responses to a situation in which "acting is experienced as a steady flow of skillful activity" (p. 8). For Dreyfus, maximum grip cannot exist at the level of mental representation but rather is sensed by the expert body as something with which it needs to fall into equilibrium. Expert performance then, relies on the expert's body being closely aligned with the environment. Affordances offered by the environment are then able to be anticipated, identified and selected in the way that most effectively meets the continually changing and persistent demands faced by the expert in their immediate situation.

Before going any further, it is necessary to differentiate the performer's awareness during performance from the psychological reality of a performance, a distinction that Chaffin (2002) and Dreyfus (2002) do not make. In Chaffin's work, this distinction remains unclear due to his focus on pre-performance procedures as opposed to what actually happens for the performer during performance. Although Dreyfus' work adopts more of a focus on the happenings of performance, he does not make the crucial distinction between awareness and reality. Therefore, it is important to note that during performance, an expert may be relying on top-down or bottom-up processes but may be unaware that they are doing so. A number of questions arise concerning psychological processes which may be influencing the performer outside of awareness. However, these are outside the scope of this present paper. Instead, this paper investigates the expert performer's experience of performance, examining the processes that the performer is aware of at the levels of phenomenology and self-report.

\section{Integrating Top-Down and Bottom-Up Processes}

Emerging over the last decade and pioneered by theorists such as Clark (1997), Hutchins (1995) and Lakoff and Johnson (1999), the Embodied Cognition (EC) paradigm shows the way toward a more integrative understanding of expertise than that offered by theorists such as Dreyfus (2002) and Chaffin (2002). The EC paradigm particularly emphasises the real-world context in which cognition occurs and the practical ends to which it is employed. Rather than being connected to complex, abstracted, overarching, preplanned, higher-order models, EC theorists posit that cognition is, rather, a situated activity. Just as a false dichotomy is created if perception and action are understood as mutually exclusive, so too are top-down and bottom-up processes viewed as sharing inextricable ties. This shift in focus transforms the human being from a Cartesian 'thinking thing' into a Heideggarian subject, an (inter)active agent constantly coping with the demands of being in the world (Andersen, 2003). The question of whether top-down or bottom-up processes are more important in expert performance is thus rendered obsolete. Attempting to demarcate higher order from more embodied processes is seen as an inevitably futile process because it is based on the false premise that these processes are able to be separated. By extension, any account of expert performance based on attempts to isolate top-down from bottom-up processes will be flawed due to oversimplification. By synthesising conceptions of expert performance offered by theorists such as Chaffin and Dreyfus, the EC paradigm lays foundations on which a more highly nuanced and less polarised account of expertise can be built.

\section{The AIR Approach to Expert Performance}

There has been only a small amount of past research that has examined an expert musician's experience of music performance. Although valuable, there are a number of difficulties with this past research. Different genres make different use of a large number of variables including musical form, convention and performance setting. These variables must have an impact at the level of phenomenology. It is hard to imagine an improvising jazz musician's performance experience being identical to that of a score-following classical musician or a heavy metal drummer. In this way, work by Berliner (1994), Monson (1996) and Sudnow (1978) examining the experience of performance for jazz musicians is valuable, but naturally cannot apply across all genres.

By conducting research investigating the musician's experience of performance across the genres of heavy metal, jazz and rock, Berger's (1999) work is more closely aligned with the aims of our research. Among a number of interesting conclusions, Berger claims to find a strong link that exists between the affective meaning of music for the performer, the structure of the music itself and the broader aspects of the performer's social life. However, as the subjectivity of the researcher powerfully shapes the conceptual framework of research, the impact of Berger's bias in his reported results is noticeable. Coupled with the strong historiographical and enthnomusicological foci of Berger's work, this limits its relevance to our research. We 
aim to allow the 'data to speak' by being more exploratory in our focus and choice of methodology.

As outlined above, the weight accorded to top-down and bottom-up processes has differed across previous accounts of expert performance. Common across all accounts however, is the static nature of the foregrounded aspect of performance. Whether emphasis is placed on higher-order processes, bodily processes, or a combination of the two, these processes are thought to occupy the musician's attention for the entire duration of performance. A performer is either 'in' their head, body or an inseparable conglomeration of both for the entire time that they are onstage. We have previously outlined another possible, more dynamic understanding of expert performance (Geeves, Christensen, Sutton, \& Mcllwain, 2008). Referred to hereafter as the AIR (Applying Intelligence to the Reflexes) approach, AIR is midway between theorists such as Dreyfus (2002), who advocate thought-free skill in expert performance, and theorists such as Chaffin (2002) who prioritise higher-order cognitive processes in expert performance. Although sympathetic with the EC paradigm, the AIR approach to expert performance views top-down and bottom-up processes as separable depending on the demands of a given context.

In a nutshell, AIR views expert performance as dynamic engagement with an activity in a way that enables the constantly changing demands of a specific context to be discerned and met effectively. Flexibility in regards to whether top-down, bottom-up or a combination of both types of processes is at the forefront of attention during performance is vital. A true expert has large amounts of information stored in LTWM and a highly refined sense of what feels right at a bodily level in any given situation. Yet their performance cannot be constrained by relying on an awareness of these processes in any sort of pre-determined or static way. An expert performer determines the amount of attention they need to pay to certain processes during performance according to the requirements of the situational demands with which they are faced in the moment. The expert must be able to make decisions on the fly and in order to achieve this, must engage in ongoing monitoring of all the processes involved in performance as they unfold.

Drawing on the potential offered by the EC paradigm as inspiration, this paper seeks to further explore ways in which expert performance draws on a wide and disparate range of resources whilst integrating a variety of different processes. Recent research conducted with Jeremy Kelshaw (JK), a professional musician, lends support to our dynamic understanding of expert performance. Carried out to investigate the experience of music performance for the professional musician, the results of this research will be explored as they are effective illustrations of the main tenets of AIR, whilst foreshadowing future research opportunities. Through an analysis of data obtained from JK, this paper seeks a more precise microanalysis of the variations in experience during performance than that offered by theorists such as Chaffin (2002) and Dreyfus (2002) Before examining the results of the research, it is necessary to briefly outline the research methodology in order to contextualise the data.

\section{Methodology}

Grounded Theory (GT) is defined by its founders Glaser and Strauss (1967) as "the discovery of theory from data systematically obtained from social research" (p. 2). The recent reworking of GT by Strauss and Corbin (1998) forms the methodology for this research program. Although only one of many possible research methodologies suitable for exploring the AIR approach, GT is the ideal methodology for this current project, a doctoral research program investigating musicians' phenomenological accounts of their performance. GT emphasises bottom-up theory building derived from strict adherence to data rather than demanding example verification or perfect description. This, combined with the emphasis placed by GT on self-reflexivity and its guards against researcher bias, is particularly useful when faced with a dearth of relevant past research and when attempting to overcome potential difficulties associated with the logistics of investigating phenomenology and experience. GT employs a piecemeal sampling approach called theoretical sampling to aid theory building. Theoretical sampling evolves throughout the course of the research, with the recruitment of each research subject being decided on the basis of conceptual variables identified through an analysis of the preceding subject's data.

A semi-structured interview carried out with JK forms the basis for the data on which this article is based. With a background in music covering more than twenty years of experience, JK is currently the bassist in Cloud Control, a self-described indie, alt-folk, pop band. Together for over four years, Cloud Control has enjoyed a moderate amount of success on the Australian music scene. JK's interview was initially intended to serve as a pilot study, with JK being chosen as an interviewee due to his friendship with the researcher (AG). It was decided upon closer inspection however, that the data emerging from this interview were rich and substantial enough to allow the interview to be included as the first in a planned program of research involving interviews with professional musicians. This program is currently being carried out to fulfill the requirements of a postgraduate psychology doctoral thesis, scheduled for submission in 2012. The necessarily unpredictable nature of theoretical sampling and the fact that this program of research is still currently being carried out make it important to stress the preliminary nature of findings reported in this article. End results of this research program may differ significantly from the results reported in this paper.

\section{Results}

JK's experience of performance is influenced by a variety of interrelated variables. Underlying JK's experience is his belief in the inherently unique nature of live music performance. Although this guarantees an element of 
uncertainty in every performance, JK was able to clearly articulate an ideal performance at the level of phenomenology. According to $\mathrm{JK}$, an ideal performance is strongly tied to the notion of vibe and connection, which are both affected by the performance environment. JK identified these variables as consistently influencing his performance experience.

Unique Nature of Musical Performance For JK, every music performance is a distinct, collaborative and non replicable creative exercise:

"It's always creating something that couldn't be created unless those people were there, at that time. It's not like a visual artwork or a video artwork which, when it's finalised, can be reproduced and copied. A live performance is unique in that it happens once and then it's gone. . . I really do enjoy being part of that creation process, of creating something that is unique to you and unique to the people that you're playing with."

The everchanging temporal and contextual variables forming the background against which music performance plays out ensure that there will always be elements of performance which $\mathrm{JK}$ is unable to prepare for. This uncertainty means that during performance, JK must remain open to the particular requirements demanded by each unique performance setting. Every performance, JK must gamble with uncertainty. To ensure that this gamble results in a satisfactory performance, JK must engage in ongoing monitoring of all the processes involved in performance in order to determine whether an optimal response requires attention to pre-planned strategies, what feels right in the moment or a combination of both.

The Blissful Moment Although there are necessarily uncertain aspects of music performance, JK was able to isolate the experience of an ideal performance:

"If you're not nervous and if it's a song that you know backwards that you're playing to a crowd that's already into what you're doing then you just go into a little bit of a zone. You just enjoy it. In that blissful moment it's the same feeling you have when you really enjoy anything I think, your body knows what to do and you just go into this trance. You just enjoy yourself and you don't have to think. It's that feeling of success and a feeling of accomplishment and privilege at the same time. It's just bliss."

Sharing common ground with Csíkszentmihályi's (1990) notion of 'flow', JK's experience of an ideal performance involves themes of intensity, transcendence, absorption, embodiment, reward and pleasure. A connection to the audience, a lack of nerves and familiarity with performance material are integral to this performance experience.

Vibe Closely related to JK's description of his ideal performance is the notion of vibe. Although this term was originally introduced into the interview by the researcher
(AG), the predilection shown by JK towards incorporating the term in his description of performance experience indicates its suitability in this context. When asked to define vibe, JK hazarded:

"It's very similar to a conversation. If you're talking to somebody that isn't a good conversationalist, in between comments, sentences or even whilst you're talking, you feel awkward. That is forefront in your mind, how awkward the conversation is. If there isn't that vibe, whatever that is, then you standing on stage in lights also becomes quite awkward. But if there is that vibe, then [performance] becomes really enthralling and really engaging."

Although difficult to define due to its enigmatic nature, vibe seems to involve a certain type of specific, unpredictable, unquantifiable, moment-to-moment feeling of synchrony, alignment and ease. With an overarching function, JK conceptualises vibe as an emergent something that binds the blissful moment together. Its nexus between individual band members, vibe can expand to fill the space between band and audience and band and song, with all three of its manifestations being interrelated.

Connection Closely tied to vibe is connection. JK defines two types of connection important in his performance experience; band-band connection and band-audience connection. Of primary importance is the connection between individual band members, which precedes the band's connection to the audience:

"Performance is not four individuals trying to create a connection to the audience. We have vibe and we don't have vibe when we rehearse and there's no audience in that. So it's only our four relationships that create or destroy that."

For JK, the whole band is greater than the sum of its parts. It is not enough for individual band members to have a connection with the audience. Rather, a connection must exist between each band member and every other individual band member. These one-to-one connections establish the band as a coherent whole. As a collective entity, this band is then able to forge a connection with the audience:

"If you as a band start forming a strong relationship before you go on then that's going to help create that relationship and that communication with the audience to a large degree."

Band-band connection is by no means guaranteed in every performance, being influenced by a number of variables in operation before a performance:

"We've tried to pin it down; we can be intentional about getting in the right head space beforehand and then end up not having that connection at a gig. Or we can be really stressed beforehand and not in a good headspace but then when we start playing it just all connects. It's a gamble and that makes it really hard because you can't guarantee that connection." 
Following on from the band-band connection is the bandaudience connection which is also characterised by an element of uncertainty:

"So much of a successful performance is a connection with the audience. We can't pin it down but I think that the better performers still look for that connection, look for that connectivity"

In addition to being influenced by band-band connection, band-audience connection is subject to influence from other factors such as the location of performance, musical genre, band status and the audience's energy levels, expectations and familiarity with band. Like band-band connection, band-audience connection can never be assured, even if band members are experiencing a feeling of connection with the audience. JK describes an incident in which there was a disjuncture between the connection the band experienced with the audience and the connection experience of some audience members:

"We were really psyched up and we played really really well. We definitely experienced some connection with people from the crowd but the reviews weren't that positive. Connection had been lost somewhere along the line."

It is unknown whether the reviewers accurately captured a disconnected audience experience or whether they somehow missed out on the connection that most of the audience were experiencing. However, the important point in both cases is, as JK states, that somewhere along the line a connection was lost. Losing connection is therefore a very real possibility during performance, inevitably resulting in an undesirable performance experience. As a result, performance for $\mathrm{JK}$ involves not only establishing band-band and band-audience connection, but also a constant checking throughout performance of how this connection is faring as well as attempts to rectify the situation if a connection has been lost.

Environment Vibe and connection are closely related to factors in the immediate environment. JK describes a number of fixed variables in the environment that are unable to be changed but which impact his experience of performance. One particularly important variable for JK is having access to a dressing room:

"As crazy as it sounds, having a dressing room to be able to sit down in and collect your thoughts before actually performing [is useful]. It can be frustrating playing local gigs where you just get off the pub floor and you've been talking to all of your friends. There's no connection between the band before we start."

Just as having access to a space in which the band can gather their thoughts before a performance begins is integral to connection, so too is the physical capacity of the performance venue:

"I always think it's so much better to play a smaller venue and to risk having people turned away than to have a bigger room that everybody can come to. That squashy feel when everybody falls over each other, as uncomfortable as that is for them, does create a huge sense of community and a sense of connection. And so that in itself creates $a$ vibe and a platform that you can work on."

In a similar fashion to the physical capacity of the performance venue, the quality of the foldback sound during performance also impacts on JK's experience:

"Good foldback sound for onstage makes such a big difference and that's never guaranteed. We do countless soundchecks that end up sounding great and then you walk onstage and it sounds awful. You don't know what's happened but you're in the hands of the console operator and off you go. You just have to soldier on and get over that."

\section{Discussion}

Having established that music performance has an inherently uncertain component, $\mathrm{JK}$ is able to pinpoint the experience of an ideal performance and identify vibe, connection and environment as being three variables that significantly affect his performance experience. The truly dynamic and integrative nature of music performance is evident in a number of strategies that JK describes implementing either before or during performance in an attempt to secure vibe and connection, and therefore, an ideal performance.

JK named two strategies implemented by Cloud Control before a performance: finding a space in which the band can be alone together before going onstage and writing a setlist. Cloud Control actively seeks to leave the performance venue before it is time for them to go on stage. Once the band has found a space in which they can be alone, they engage in exercises designed to prepare them for performance:

"We've started singing together beforehand. That gets us into a positive frame of mind when we start laughing and start enjoying ourselves. I've started giving really corny but awesome speeches before we play. There have been a lot of times when we've been really scattered and I just say "This has been really scattered but all these people have turned up to see us so let's just rock this". That kind of thing really helps. It's a really good way of getting people on the same wavelength. Rather than thinking about different things everyone starts to think about the performance and that helps to no end"

Singing together and listening to JK's pep talk are designed to foster a connection among band members and to instil a specific mood in the band which will remain regardless of any uncontrollable events that may occur in the lead up to performance or whilst onstage. Cloud Control enjoy singing together and this activity invokes a good mood in the band members as well as creating an initial space for shared attention. JK's pep talk realistically outlines the performance context, reiterating audience expectations and the sometimes less than ideal circumstances in which the 
band may find itself. This then serves to further consolidate the group's shared attention around the impending performance.

Before a performance, Cloud Control determines a specific setlist based on a selection process anticipating material that will dovetail neatly with the inferred needs of the audience:

"If we know that we're playing to a pretty similar crowd that we may have played to in the last two or three months, we try to mix things up so that they're not bored and so that there is that hint of freshness. You introduce new, fresh stuff and play your golden oldies and then everybody's happy."

By compiling a setlist in this way, Cloud Control seeks to optimise the chance that they will be able to connect with the audience, irrespective of what other variables may come into play during performance. Although the setlist is predetermined before every Cloud Control performance, it is also free to vary to a certain extent according to the demands of the situation. Similarly, there are elements of each song which are free to vary according to situational demands:

"If things are awkward then you change the setlist up. You can take proactive steps to try to get people more into it. We find it comfortable to know exactly where the song is going to head in terms of length and structure. But, although there is always something that is set, it just becomes appropriate sometimes to add, to change or to subtract from that. They're probably more ornamental things, just finishing touches as opposed to the root of the song. So I may add just a few more notes into a baseline but keep the whole rhythm the same. Or, there are times when Al [the lead singer and guitarist] will roll with how he's feeling at the time in regards to how to express, phrase or sing a melody."

By approaching performance in this way, JK and Cloud Control ensure that performance remains open to the performers meeting varying contextual demands in a way which feels right for them at the time of performance. At the same time however, the performance is anchored in an unchanging overall structure. This remains unchanged and allows the band and the performance to continue to function smoothly as a coherent whole.

In addition to pre-performance strategies, JK also described a number of tactics that are executed during a performance in an attempt to foster vibe and connection. For $\mathrm{JK}$, exercising agency over variables he believes to be under his control whilst onstage is an important component of attempting to create vibe, and therefore, the experience of an ideal performance:

"It's about taking as much control as you can. If we let ourselves think everything is out of control, then it can be the most painful experience ever. The things you can control [are] your attitude, how much energy you're putting into things and what you say."
However, JK also describes how important it is for a performer not to force vibe:

"If something's not going to happen, you can't force it. We've tried to force it, I've tried to force it, other people have tried to force it and you just can't. If it's not there to be had then that's fine and you just give it your best and move on. Forcing funny band wit and banter between songs just comes across awkwardly if it's not natural. It comes across really clearly to people that you're not really having a good time."

Ultimately, JK needs to be completely in tune with the demands of the situation in order to ascertain the amount of intentionality he needs to exercise in accordance with the amount of vibe present, and the extent to which this intentionality will be able to influence vibe. If appropriate, JK may mindfully attempt to exercise agency over attitude, energy and interaction with the audience, the three onstage variables that he views as within his control, in an attempt to increase vibe. However, exercising this amount of agency over these variables may make a performance feel forced, thereby ruining any vibe that may be present. JK's performance experience is contingent upon his ability to work out just what is within his control and to what degree. It also depends on his acceptance of that which is out of his control, all in a way which maximises potential for vibe:

"You've just gotta take control of stuff that you can control and if it's out of your control then that's fine. But how you respond to that is in your control, so just running with that is all you can do really."

Cloud Control also engage in various onstage tactics designed to facilitate connection. To foster band-band connection, the members of Cloud Control assure that they maintain eye contact with one another:

"A huge proactive thing we try to do is to look at each other. It's surprising how hard that is when a gig isn't going so well. You may feel a bit embarrassed and to look someone in the eyes who is a part of that with you is actually really hard. But we've agreed that that's what we need to do and so we try to do that as much as we can."

Consolidating band-audience connection relies on a number of different strategies. For JK, active demonstration of the performers' intentionality can be important for bandaudience connection:

"You actually do have to choose to have a good time. Sure [elements of performance] may be bad but you just have to give it your best and people will respect that. If we know that the sound is bad, we don't let it become the governing factor of a gig. Obviously you're thinking about it but you're not letting that rule the gig for you. The key is to just try and be intentional. People pick up laziness and don't appreciate it. They like you being intentional ... you can't just rest on your laurels." 
Additionally, demonstrating technicality within a piece can also be appropriate at times and serve to further enhance band-audience connection:

"As soon as you go into that technical space of having to think, most people shut down, they become expressionless, they stand still and don't exhibit exactly what they're feeling. But that can be appropriate. You're communicating that this is difficult to play so I'm taking the time to actually play it well because I think it is worth playing well."

During performance, the performer may try to address band-audience connection if it is sensed that this connection has never been established or that it is waning. If this is the case, JK and Cloud Control may try talking more with the crowd, putting more energy into a performance or displaying enjoyment of the performance to the audience:

"The better performers make proactive steps to increase connection or get it back if it has been lost midset. Having a literal conversation, talking to the crowd, that always helps. I think that putting as much energy as you can into something helps as well. It's always easier if you have that vibe and that connection to put energy in but if you don't have that connection then it's still an opportunity and you still have to give it your best. We try to have fun first and foremost and that gets displayed to the audience who can then engage with that."

JK believes that music performance always involves unpredictable elements and environmental factors that are outside of his control. However, despite (or possibly on account of) this unpredictability, these strategies represent proactive attempts made by $\mathrm{JK}$ and Cloud Control in an effort to increase the likelihood that vibe and connection will be present in performance and that therefore an ideal performance will be experienced. These strategies are effective illustrations of the complexity involved in expert performance, a complexity that is also central in the AIR approach to understanding expert performance. They demonstrate that the spotlight of JK's attention must pan across a vast array of disparate performance processes and levels at different phases of performance in order to meet the specific demands of the performance situation. On stage, some moments may call for the focus of JK's attention to be on higher-order control processes, others for a closer sense of bodily attunement and still others for a combination of both of these. An exploration of these strategies demonstrates just how deeply enmeshed the various elements of performance are. Supporting the AIR approach, these strategies illustrate the dynamicism involved in expert performance and the flexibility that is required of the expert performer. In order to meet the demands of the situation and hence, to increase the likelihood of experiencing an ideal performance, JK must be aware of what is occurring across a number of different performance processes and at a number of different levels within these processes. In accordance with the requirements of specific situational demands in any given moment of performance, the expert performer must also be able to flexibly allocate a shifting amount of attention (or inattention) to performance processes and their various layers.

\section{Conclusion}

An exploration of JK's account of his performance experience illustrates the dynamic and integrative nature of expert performance. Due to the inherently uncertain elements of music performance, JK and Cloud Control must execute a number of strategies in order to increase the likelihood that vibe and connection will be present, irrespective of variables that are outside their control. Effective execution of these strategies requires JK to engage in ongoing monitoring during performance, whereby shifting amounts of attention are allocated to different levels of both top-down and bottom-up processes in order to meet the specific demands of a given performance moment. JK's account effectively illustrates the AIR approach to understanding expert performance. It is hoped that future research compiling data from numerous interviews and sources as well as using different research methodologies will further unlock the potential that the AIR approach holds for understanding expert performance.

\section{References}

Andersen, M. L. (2003). Embodied Cognition. Artificial Intelligence, 149, 91-130.

Berger, H. M. (1999). Metal, rock and jazz: Perception and the phenomenology of musical experience. Hanover \& London: University Press of New England.

Berliner, P. F. (1994). Thinking in jazz: The infinite art of improvisation. Chicago, IL: University of Chicago.

Chaffin, R. (2002). Expert memory. In R. Chaffin, G. Imreh \& M. Crawford (Eds.), Practicing perfection: Memory and piano performance (pp. 66-73). London: Lawrence Erlbaum Associates.

Clark, A. (1997). Being there: Putting brain, body and world together again. Cambridge, Massachusetts: MIT Press.

Dreyfus, H. L. (2002). Intelligence without representation Merleau-Ponty's critique of mental representation: The relevance of phenomenology to scientific explanation. Phenomenology and the Cognitive Sciences, 1, 367-383.

Ericsson, K. A., \& Kintsch, W. (1995). Long-term working memory. Psychological Review, 102(2), 211-245.

Geeves, A., Christensen, W., Sutton, J., \& McIlwain, D. (2008). Critical Review of Practicing Perfection, by Chaffin, Imreh, \& Crawford. Empirical Musicology Review, 3(3), 163-172.

Glaser, B. G., \& Strauss, A. L. (1967). The discovery of grounded theory: Strategies for qualitative research. Hawthorne, New York: Aldine Publishing Company.

Hutchins, E. (1995). Cognition in the wild. Massachusetts: MIT Press. 
Lakoff, G., \& Johnson, M. (1999). Philosophy in the flesh: The embodied mind and its challenge to Western thought. New York: Basic Books.

Monson, I. (1996). Saying something: Jazz improvisation and interaction. Chicago, IL: University of Chicago.

Strauss, A. L., \& Corbin, J. (1998). Basics of qualitative research: Techniques and procedures for developing grounded theory (2nd ed.). California: SAGE Publications.

Sudnow, D. (1978). Ways of the hand: The organisation of improvised conduct. London: Routledge \& Kegan Paul.

\section{Citation details for this article:}

Geeves, A., McIlwain, D., Sutton, J., Christensen, W. (2010). Expanding Expertise: Investigating a Musician's Experience of Music Performance. In W. Christensen, E. Schier, and J. Sutton (Eds.), ASCS09: Proceedings of the 9th Conference of the Australasian Society for Cognitive Science (pp. 106-113). Sydney: Macquarie Centre for Cognitive Science.

DOI: 10.5096/ASCS200917

URL:

http://www.maccs.mq.edu.au/news/conferences/2009/AS CS2009/html/geeves.html 